\title{
Short- and long-term outcomes of single bare metal stent versus drug eluting stent in nondiabetic patients with a simple de novo lesion in the middle and large vessel
}

Yue-jin Yang*1, Sheng Kang*2, Bo Xu1 ${ }^{1}$, Ji-lin Chen ${ }^{1}$, Shu-bin Qiao1, Xuewen Qin ${ }^{1}$, Min Yao ${ }^{1}$, Jue Chen ${ }^{1}$, Yong-jian Wu${ }^{1}$, Hai-bo Liu ${ }^{1}$, Jin-qing Yuan ${ }^{1}$, Shi-jie You${ }^{1}$, Jian-jun $\mathrm{Li}^{1}$, Jun Dai ${ }^{1}$ and Run-lin Gao ${ }^{1}$

Address: ${ }^{1}$ Department of Cardiology, Cardiovascular Institute \& Fu Wai Hospital, Chinese Academy of Medical Sciences \& Peking Union Medical College, Bei Li Shi Rd 167, Beijing, 100037, PR China and 2Department of Cardiology, Rui Jin Hospital, Shanghai Jiaotong University School of Medicine, Rui Jin 2nd Rd 197, Shanghai, 200025, PR China

Email: Yue-jin Yang* - yangyjfw@yahoo.com.cn; Sheng Kang* - kangsheng2008@163.com; Bo Xu - Xubofw@263.com; Jilin Chen - Chenjilinfw@163.com; Shu-bin Qiao - Qiaoshubinfw@263.net; Xue-wen Qin - Qinxuewenfw@yahoo.com; Min Yao - Yaominfw@263.net; Jue Chen - Chenjuefw@yahoo.com; Yong-jian Wu - Wuyongjianfw@263.net; Haibo Liu - Liuhaibofw@163.com; Jin-qing Yuan-Yuanjinqingfw@yahoo.com; Shi-jie You - Youshijiefw@163.com; Jianjun Li - Lijianjunfw@263.net; Jun Dai - Daijunfw@yahoo.com; Run-lin Gao - Gaorunlinfw@163.com

* Corresponding authors

Published: 6 August 2008

Journal of Translational Medicine 2008, 6:42 doi:10.1 186/1479-5876-6-42
Received: 17 June 2008

Accepted: 6 August 2008

This article is available from: http://www.translational-medicine.com/content/6/1/42

(c) 2008 Yang et al; licensee BioMed Central Ltd.

This is an Open Access article distributed under the terms of the Creative Commons Attribution License (http://creativecommons.org/licenses/by/2.0), which permits unrestricted use, distribution, and reproduction in any medium, provided the original work is properly cited.

\begin{abstract}
Objective: This study was aimed to investigate the short- and long-term outcomes of percutaneous coronary intervention (PCl) between single bare metal stent (BMS) and single drug eluting stent (DES) in nondiabetic patients with a simple de novo lesion in the middle and large vessel.

Methods: Two hundred and thirty-five consecutive patients with a simple de novo lesion in the middle and large vessel were treated with BMS or DES in our hospital from Apr. 2004 to Dec. 2004.

The inclusion criteria: a simple de novo lesion in the middle and large vessel, stent diameter $\geq 3.0 \mathrm{~mm}$, stent length $\leq 18 \mathrm{~mm}$, the exclusion criteria: diabetes mellitus, left main trunk disease and left ventricular ejection fraction $\leq$ $30 \%$. Of them, there were 150 patients in BMS group and 85 patients in DES group, and the rates of lost to follow up were $6.7 \%$ and $1.2 \%$ respectively.

Results: BMS group had lower hypercholesteremia rate $(22.0 \%$ vs $38.8 \%)$ and higher proportion of TIMI grade $0(I 2 \%$ vs $I .2 \%$ ) than DES group (all $P<0.05)$, but both groups had similar stent length $(16.16 \pm 2.81 \mathrm{~mm}$ vs 16.06 $\pm 2.46 \mathrm{~mm})$ and stent diameter $(3.85 \pm 3.07 \mathrm{~mm}$ vs $3.19 \pm 0.24 \mathrm{~mm})$ after procedure, in-segment restenosis rate ( $0 \%$ vs $1.2 \%$ ) and target lesion revascularization (TLR, $2.0 \%$ vs $2.4 \%$ ) at 6 -month follow-up (all $P>0.05$ ). No difference was found in TLR (I.3\% vs I.2\%, P = I.00) and recurrent myocardial infarction (Re-MI) $(0 \%$ vs $1.2 \%, P$ $=0.36)$, cardiac death $(0.7 \%$ vs I. $2 \%, P=I .00)$ between $I$ - and 3 -year. So were TLR $(6.0 \%$ vs $5.9 \%, P=0.97)$, ReMI $(0 \%$ vs $2.4 \%, P=0.06)$, cardiac death $(2.0 \%$ vs $3.5 \%, P=0.48)$ and major adverse cardiac events (MACE, $8.7 \%$ vs $10.6 \%, P=0.63)$, cardiac death-free cumulative survival ( $98.7 \%$ vs $97.7 \%, P=0.56)$, TLR-free cumulative survival (94.0\% vs $94.1 \%, P=0.98)$ and Re-Ml-free cumulative survival $(100 \%$ vs $97.7 \%, P=0.06)$ at 3 -year follow-up.
\end{abstract}

Conclusion: The single BMS has similar efficacy and safety to single DES in nondiabetic patients with a simple de novo lesion in the middle and large vessel at short- and long-term follow-up. 


\section{Background}

Drug eluting stent (DES) has dramatically reduced restenosis risks compared with bare metal stent (BMS) and conventional balloon angioplasty [1-3]. Angiographic analysis found that the majority of DES restenosis were focal, localized, and bordered by segments with no angiographic evidence of neointima, while BMS restenosis tended to be diffuse or proliferative $[4,5]$. Thereby, DES has revolutionized revascularization therapy and is rapidly becoming the standard for percutaneous coronary intervention (PCI).

Although the incidence of late stent thrombosis is very low, DES may increase the risk for late events, especially associated with discontinuation of dual anti-platelet therapy $[6,7]$. Considering that the patients are difficult in anti-platelet compliance and more drug cost, we have to ask whether all lesions need DES and what specific lesion types are independent of DES therapy. Factors known to increase the risks of in-stent restenosis include smaller vessel diameter, prior restenosis, length of stented vessel, and diabetes mellitus $[8,9]$. However, few of study reported that a simple de novo lesion, for example, lesion type A/B1[10,11] in the middle and large vessel was treated with single BMS vs single DES at short- and longterm follow-up.

Thus we investigated the efficacy and safety of single BMS vs. single DES in nondiabetic patients with a simple de novo lesion in the middle and large vessel at 6-month, 1year and 3-year follow-up in real world.

\section{Methods \\ Study population}

Demographic and procedural data were retrieved from a dedicated PCI database between Apr 2004 to Dec 2004 at Fu Wai hospital. Only a simple de novo lesion in single middle and large vessel, stent diameter $\geq 3.0 \mathrm{~mm}$, stent length $\leq 18 \mathrm{~mm}$ were included. The unprotected left main disease $\geq 50 \%$ stenosis, left ventricular ejection fraction $\leq$ $30 \%$ and diabetic patients including definite diabetic patients, newly diagnosed patients and diet controlled patients were the major exclusion criteria. Finally, there were 150 patients in BMS group and 85 patients in DES group.

\section{Procedures and relevant medications}

All patients were pretreated with aspirin and either ticlopidine or clopidogrel. A $300 \mathrm{mg}$ loading dose of clopidogrel was administered before the procedure if patients were not pretreated. During the procedure, a bolus dose of unfractionated heparin (100 U/kg) was administered after femoral or radial artery sheath insertion, with repeat bolus given as needed to maintain activated cloting time between 250 to 300 seconds. The administration of glyc- oprotein IIb/IIIa inhibitors Tirofiban was left to the operator's discretion. The operators were free to use the BMS or DES that they considered best. BMS included Coroflex Delta, Driver, Express 2, micro-Driver, Multi-Link Mini Vision, Multi-Link Vision, Multi-Link Zeta, Mustang and Tecnic Carbostent, DES included Cypher, Cypher Select, Firebird and Taxus Express 2.

All patients kept on aspirin therapy (300 mg/day for 3 months and $100 \mathrm{mg} /$ day in lifelong time). Ticlopidine (500 mg/day) or Clopidogrel (75 mg/day) was administered for 6 to 12 months after DES implantation or for 3 months in BMS group.

\section{Clinical definitions and follow-up}

The clinical data were reviewed to obtain from a computerized database by specialized personnel at the cardiovascular interventional center in Fu Wai hospital. Risk factors for coronary artery disease that were tabulated included diabetes mellitus (only if treated medically), hypertension (only if treated medically), and hyperlipidemia (only if treated medically or if serum cholesterol was $240 \mathrm{mg} / \mathrm{dl}$ ), but in this study we excluded diabetic patients. The diagnosis of acute myocardial infarction (AMI) during hospitalization and follow-up was based on the presence of new $Q$ wave on electrocardiogram and/or elevation of creatine kinase $\mathrm{MB}$ to at least three times the upper limit of the normal range [12]. Simpsons method was used for LVEF measurement by the blind to two observers.

Quantitative coronary angiography analysis was made using a validated, edge detection system (MED CON QCA software). Lesion length was defined as the distance from the proximal to the distal shoulder of the lesion. The degree of stenosis before and after angioplasty was measured after intracoronary injection of nitrates in the view showing the most severe stenosis, and expressed as the minimum lumen diameter and the linear percent lumen diameter reduction, using the average diameter of the nearest proximal and distal normal segments as the reference. In-segment restenosis was defined as diameter stenosis $\geq 50 \%$ within a previously stented segment (5 mm proximal and distal to stent) using follow-up angiograms. A blood flow rate of grade 1 or higher according to the classification of the Thrombolysis in Myocardial Infarction (TIMI) trial.

Stent thrombosis was defined as occlusion of either vessel or thrombus within or adjacent to a previously successfully stented vessel from angiographic evidence or, in the absence of angiographic confirmation, either AMI in the distribution of the treated vessel or death not clearly attributable to other causes [13]. In-stent thrombosis was categorized according to the timing of the event into: acute thrombosis (within 24 hours after the procedure), 
subacute thrombosis (from postprocedure 1 to 30 days), late thrombosis ( $>30$ days and $<1$ year) and very late thrombosis ( $\geq 1$ year). Target lesion revascularization (TLR) was defined as any symptom driven coronary artery bypass graft or repeat PCI for restenosis or closure of the target lesion. MACE included recurrent myocardial infarction (Re-MI), cardiac death and TLR. Data for patients who did not have MACE were censored either at 3 years or at the last known time of follow-up. Data for patients who died before 3-year follow-up were censored at the time of death.

A patient's clinical status was assessed by outpatient interview or telephone conversation. All patients were asked to return for coronary angiography approximately six months after the procedure, or earlier if angina symptoms occurred. Telephone interviews or outpatient interview were repeated at twelve months and three years after the procedure. Relevant data were collected and entered into a computerized database by specialized personnel at the cardiovascular interventional center in Fu Wai hospital.

\section{Statistical analysis}

All statistical analyses were performed with SPSS for Windows (version 10.0, Chicago). Continuous variables were described as mean $\pm \mathrm{SD}$, and categorical variables were reported as percentages or proportions. The comparisons of continuous variables were performed with unpaired ttests (normal distribution) and nonparametric MannWhitney U test (skew distribution). The analysis of categorical variables was performed with Fisher's exact test and Chi-square test. Kaplan-Meier time-to-event estimates was used for the primary events at 1-year and 3-year of follow-up, which were compared with the log-rank test between BMS group and DES group. All reported $P$ values were two-sided, and a P value $<0.05$ was considered statistically significant.

\section{Results}

Baseline clinical characteristics were shown in table 1 . Compared to DES group, the patients in BMS group had lower hypercholesteremia rate $(22.0 \%$ vs $38.8 \%, \mathrm{P}=$ $0.006)$, but age, gender, other risk factors for coronary artery disease and left ventricular function were similar in the two groups (all $\mathrm{P}>0.05$ ).

During procedure and in-hospital, BMS group had higher proportion of TIMI grade 0 than DES group $(12.0 \%$ vs $1.2 \%, \mathrm{P}<0.05)$, but other variable including calcified lesion $(\%)$, lesion length $(\mathrm{mm})$, stent diameter $(\mathrm{mm})$, percentage of lumen stenosis (\%), balloon predilatation $(\%)$, stent length (mm), post-dilatation (\%), vessel dissection (\%), postprocedural residual stenosis (\%) and inhospital outcomes did not significantly differ (all P > $0.05)$ in table 2. Despite that BMS had higher acute thrombosis rate than DES ( $3.3 \%$ vs $0 \%, \mathrm{P}=0.162)$, these patients recovered reperfusion after thrombolysis and intra-aortic balloon pump therapy, there were not in-hospital TLR and death in BMS group.

Repeat coronary angiography at 6-month follow-up showed similar acute and subacute thrombosis (\%), late thrombosis (\%), in-segment restenosis (\%), TLR (\%) and composite of cardiac death or Re-MI (\%) in the two groups (all $\mathrm{P}>0.05$ ) in table 3 .

The rates of lost to follow up at 3-year follow-up were $6.7 \%$ and $1.2 \%$ between BMS and DES group. The both groups had not significant differences in primary events including TLR $(1.3 \%$ vs $1.2 \%, \mathrm{P}=1.00)$ and recurrent myocardial infarction (Re-MI) ( $0 \%$ vs $1.2 \%, \mathrm{P}=0.36$ ) or cardiac death $(0.7 \%$ vs $1.2 \%, \mathrm{P}=1.00)$ between 1 - and 3year, So were Re-MI (\%), cardiac death (\%), TLR (\%) and MACE (\%) at 1- and 3-year follow-up (all P > 0.05) in table 4 .

The cumulative survival free of cardiac death in BMS group vs DES group was $100 \%$ vs $100 \%$ (Log rank $\mathrm{P}=$ 1.000 ) at 1 -year and $98.67 \%$ vs $97.65 \%$ (Log rank $\mathrm{P}=$ 0.559 ) at 3-year follow-up (Fig. 1). Similarly, TLR-free cumulative survival between BMS group and DES group was $95.33 \%$ vs $95.29 \%(\log \operatorname{rank} \mathrm{P}=0.978)$ at 1 -year and

Table I: Baseline Clinical Characteristics

\begin{tabular}{|c|c|c|c|}
\hline Characteristics & $\begin{array}{l}\text { BMS group } \\
(\mathrm{N}=150 \mathrm{Pts})\end{array}$ & $\begin{array}{l}\text { DES group } \\
(\mathrm{N}=85 \mathrm{Pts})\end{array}$ & $P$ value \\
\hline Age (years) & $56.66 \pm 11.72$ & $58.26 \pm 11.14$ & 0.307 \\
\hline Male (\%) & 80.7 & 78.8 & 0.734 \\
\hline Hypercholesteremia (\%) & 22.0 & 38.8 & 0.006 \\
\hline Hypertension (\%) & 50.7 & 60.0 & 0.168 \\
\hline Family history of CAD (\%) & 3.3 & 3.5 & 0.937 \\
\hline Smoking (\%) & 37.3 & 38.8 & 0.821 \\
\hline Unstable angina history (\%) & 72.0 & 75.3 & 0.198 \\
\hline Acute myocardial infarction (\%) & 34.7 & 23.5 & 0.075 \\
\hline LVEF (\%) & $63.24 \pm 23.23$ & $68.43 \pm 17.06$ & 0.108 \\
\hline
\end{tabular}

Note: Pts, patients; CAD, coronary artery disease; LVEF, left ventricular ejection fraction. 
Table 2: Angiographic characteristics and in-hospital outcomes

\begin{tabular}{|c|c|c|c|}
\hline Characteristics & $\begin{array}{l}\text { BMS group } \\
(\mathrm{N}=150 \mathrm{Pts})\end{array}$ & $\begin{array}{l}\text { DES group } \\
(\mathrm{N}=85 \mathrm{Pts})\end{array}$ & $P$ value \\
\hline Calcified lesion (\%) & & & 0.282 \\
\hline None & 79.9 & 70.6 & \\
\hline Slightness & 15.4 & 18.8 & \\
\hline Moderation & 3.4 & 8.2 & \\
\hline Severity & 1.3 & 2.4 & \\
\hline Lesion length (mm) & $12.60 \pm 4.05$ & $11.65 \pm 3.09$ & 0.062 \\
\hline Percentage of lumen stenosis (\%) & $87.82 \pm 8.70$ & $85.73 \pm 8.48$ & 0.075 \\
\hline TIMI grade & & & 0.030 \\
\hline 0 & 12.0 & 1.2 & \\
\hline I & 3.3 & 2.4 & \\
\hline 2 & 14.7 & 17.6 & \\
\hline 3 & 70.0 & 78.8 & \\
\hline Balloon predilatation (\%) & 63.3 & 56.5 & 0.300 \\
\hline Stent length $(\mathrm{mm})$ & $16.16 \pm 2.81$ & $16.06 \pm 2.46$ & 0.782 \\
\hline Stent diameter $(\mathrm{mm})$ & $3.85 \pm 3.07$ & $3.19 \pm 0.24$ & 0.050 \\
\hline Post-dilatation (\%) & 15.4 & 25.6 & 0.060 \\
\hline Vessel dissection (\%) & 0 & 1.2 & 0.363 \\
\hline Acute thrombosis (\%) & 3.3 & 0 & 0.162 \\
\hline Postprocedural residual stenosis (\%) & $0.21 \pm 1.15$ & $0.29 \pm 1.61$ & 0.656 \\
\hline In-hospital TLR (\%) & 0 & 1.2 & 0.183 \\
\hline In-hospital cardiac death (\%) & 0 & 0 & ....... \\
\hline
\end{tabular}

Note: Pts, patients; TLR, target lesion revascularization.

$94.00 \%$ vs $94.12 \%$ (Log rank P = 0.984) at 3-year followup (Fig. 2). Noticeably, there was a trend towards a decrease of Re-MI-free cumulative survival in the DES group compared with the BMS group at 1-year (98.82\% vs $100 \%$, Log rank $P=0.183)$ and 3-year follow-up (97.65\% vs $100 \%$, Log rank $P=0.059$ ) (Fig. 3 ).

\section{Discussion}

This is the first study to investigate efficacy and safety of single BMS vs. single DES in nondiabetic patients with a simple de novo lesion in the middle and large vessel at 3year follow-up in real world. The present study found that both DES group and BMS group had similar acute and subacute thrombosis (\%), late thrombosis (\%), in-segment restenosis (\%), TLR (\%), composite of cardiac death or Re-MI (\%) at 6-month follow-up, so were Re-MI (\%), cardiac death (\%), TLR (\%) and MACE (\%) at 1- and 3year follow-up in the two groups, furthermore, nonsignificant difference in the cardiac death-free and TLR-free cumulative survival rates except that there was a trend towards a decrease of Re-MI-free cumulative survival rate in DES group compared with BMS group at 1- and 3-year follow-up (all P > 0.05).

The previous study found that vessel diameter was an established predictor of angiographic outcome after catheter-based intervention, with a higher restenosis rate in smaller vessels [14]. Thereby, at the time of these pilot studies, sirolimus-eluting stents were only available in a $3.0 \mathrm{~mm}$ or $3.5 \mathrm{~mm}$ diameter, limiting treatment to relatively large vessels, these sirolimus-eluting stents showed $0 \%$ restenosis at 4-month [15], 6-month [16], and 12month [17]. Later, a study demonstrated that the classic inverse relationship between vessel diameter and restenosis rate was seen in the BMS group but not in the sirolimus-eluting stent group [18], and vessel sizes of 2.5 - $3.5 \mathrm{~mm}$ were allowed in the subsequent randomized study with the sirolimus-coated Bx velocity balloon-

Table 3: The procedural characteristics and 6-month outcomes

\begin{tabular}{|c|c|c|c|}
\hline Characteristics & $\begin{array}{l}\text { BMS group } \\
(\mathrm{N}=150 \mathrm{Pts})\end{array}$ & $\begin{array}{c}\text { DES group } \\
(\mathrm{N}=85 \mathrm{Pts})\end{array}$ & $P$ value \\
\hline Subacute thrombosis (\%) & 0 & 0 & $\ldots \ldots$. \\
\hline Late thrombosis (\%) & 0 & 2.4 & 0.129 \\
\hline In-segment restenosis (\%) & 0 & 1.2 & 0.258 \\
\hline Composite of cardiac death or Re-MI (\%) & 0 & 1.2 & 0.362 \\
\hline TLR (\%) & 2.0 & 2.4 & 1.000 \\
\hline
\end{tabular}

Note: Pts, patients; Re-MI, recurrent myocardial infarction; TLR, target lesion revascularization. 
Table 4: Clinical outcomes at I-year and 3-year follow-up between DES group and BMS group

\begin{tabular}{|c|c|c|c|c|c|c|c|c|c|}
\hline \multirow[t]{2}{*}{ Events } & \multicolumn{3}{|c|}{ I-year follow-up } & \multicolumn{3}{|c|}{ 3-year follow-up } & \multicolumn{3}{|c|}{$\begin{array}{l}\text { Between I-year and } \\
\text { 3-year follow-up }\end{array}$} \\
\hline & $\begin{array}{l}\text { BMS group } \\
(\mathrm{N}=150 \mathrm{Pts})\end{array}$ & $\begin{array}{l}\text { DES group } \\
(\mathrm{N}=85 \mathrm{Pts})\end{array}$ & $P$ & $\begin{array}{l}\text { BMS group } \\
(\mathrm{N}=150 \mathrm{Pts})\end{array}$ & $\begin{array}{l}\text { DES group } \\
(\mathrm{N}=85 \mathrm{Pts})\end{array}$ & $P$ & $\begin{array}{l}\text { BMS group } \\
(\mathrm{N}=150 \mathrm{Pts})\end{array}$ & $\begin{array}{l}\text { DES group } \\
(\mathrm{N}=85 \mathrm{Pts})\end{array}$ & $P$ \\
\hline Re-MI (\%) & 0 & 1.2 & 0.36 & 0 & 2.4 & 0.06 & 0 & 1.2 & 0.36 \\
\hline Cardiac death (\%) & 1.3 & 2.4 & 0.62 & 2.0 & 3.5 & 0.48 & 0.7 & 1.2 & 1.00 \\
\hline TLR (\%) & 4.7 & 4.7 & 1.00 & 6.0 & 5.9 & 0.97 & 1.3 & 1.2 & 1.00 \\
\hline MACE (\%) & 6.0 & 7.1 & 0.75 & 8.7 & 10.6 & 0.63 & 2.7 & 3.5 & 0.71 \\
\hline
\end{tabular}

Note: Pts, patients; Re-MI, recurrent myocardial infarction; TLR, target lesion revascularization; MACE, major adverse cardiac events.

expandable stent in the treatment of patients with de novo native coronary artery lesions (RAVEL) trial, yet lesions still had to be covered with one stent [19].

Currently, based on a lot of studies, people began to believe that the restenosis at the site of stent implantation seen in $15-60 \%$ of patients was dependent on various confounding factors, such as the presence or absence of diabetes mellitus, the size of the targeted coronary artery, the length of the coronary lesion, and the degree of vessel patency achieved by the intervention [20-25]. DES has been shown to reduce the risk of restenosis compared with BMS $[1,19,25,26]$. Despite that treatment of specific lesions types, especially in stent restenosis and distal stenosis of left main coronary, as well as diabetic patients, remains suboptimal with DES, whereas considering that

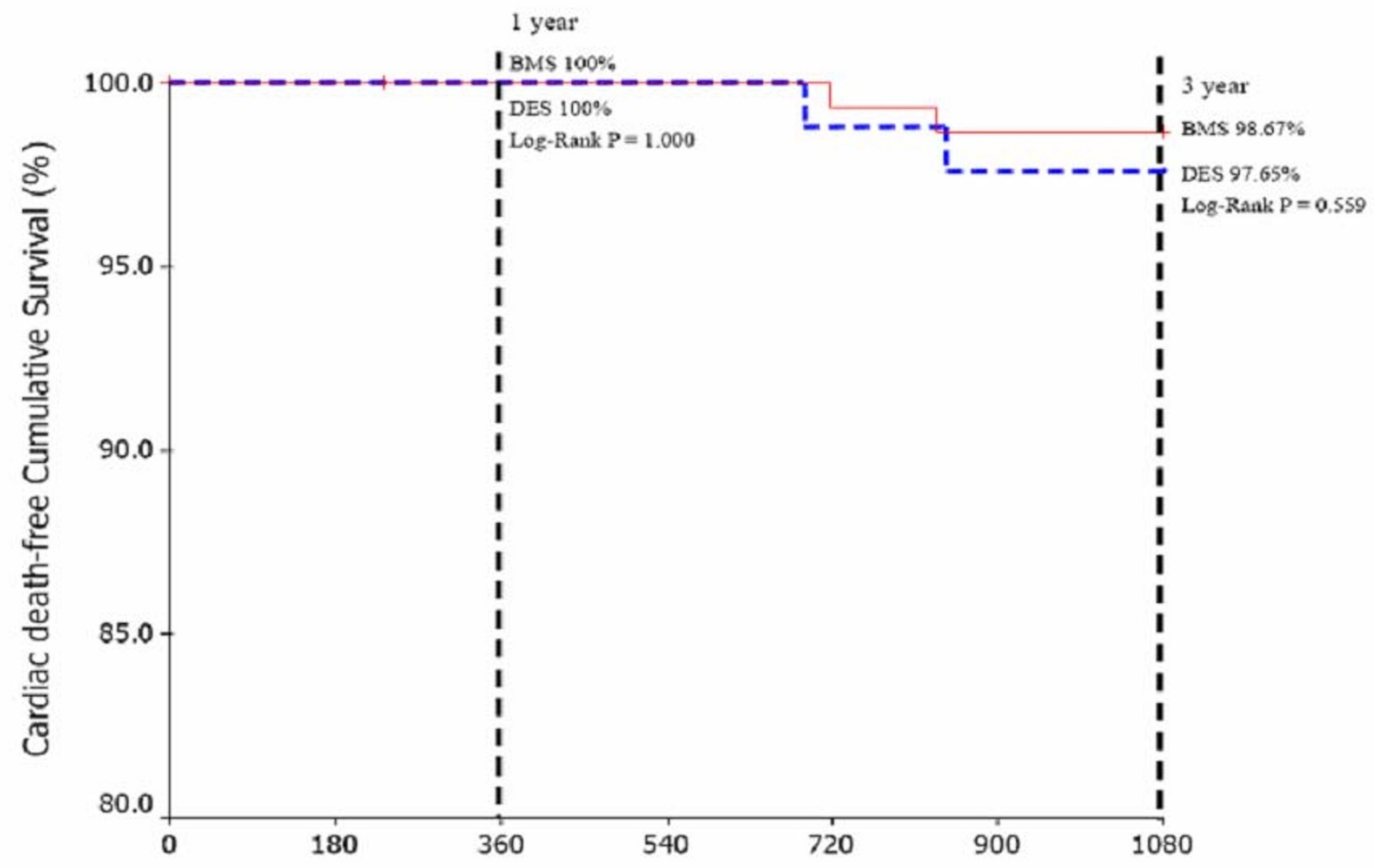

Time days

Figure I

The Cardiac death-free cumulative survival between BMS group and DES group at I-year and 3-year followup. 


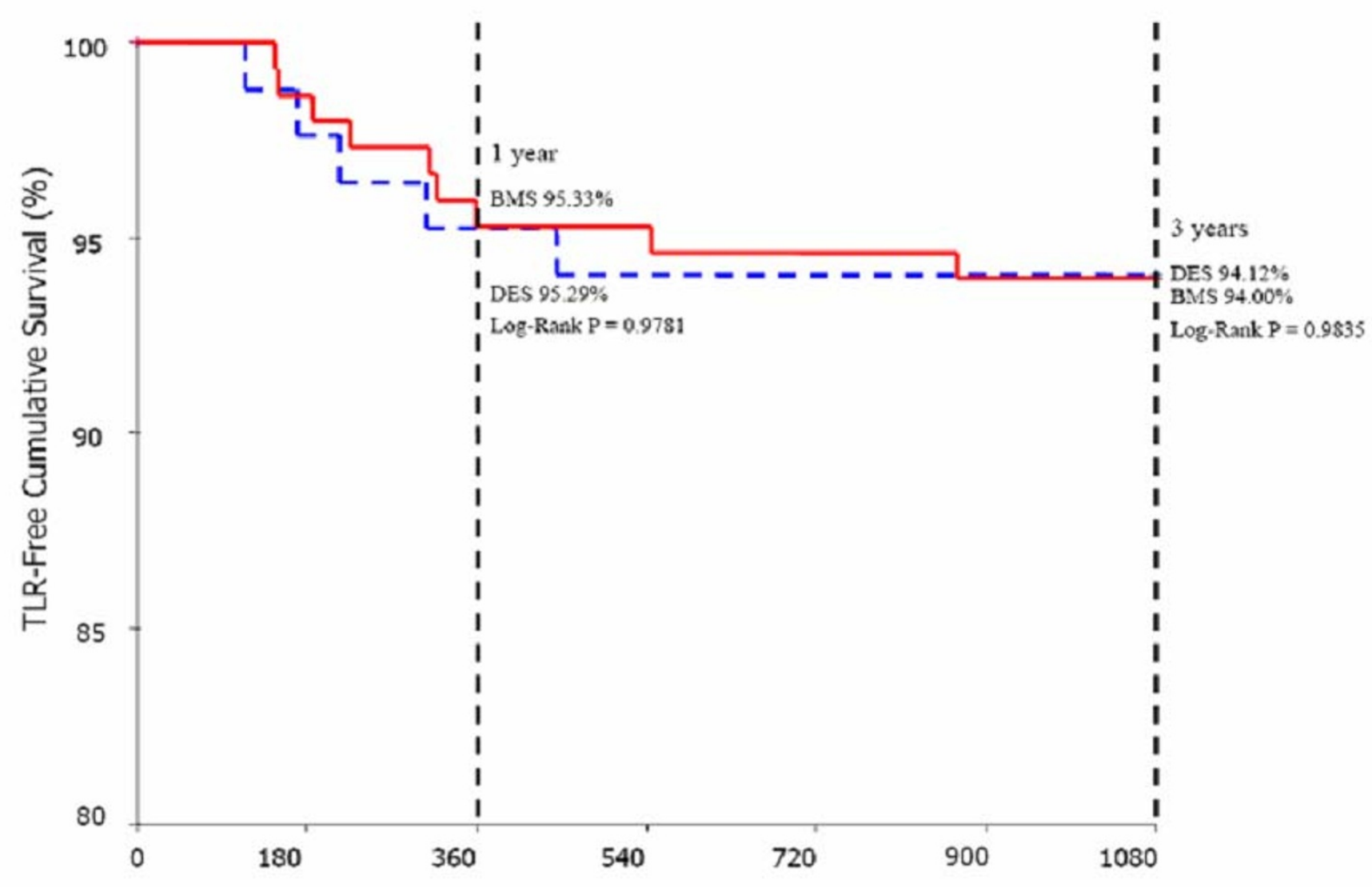

Time days

Figure 2

TLR-free cumulative survival between BMS group and DES group at I-year and 3-year follow-up.

DES practice including complex interventions is safe and associated with significant reductions in clinical driven repeat revascularization rates [27]. Moreover, DES also can effectively treat in-stent restenosis and saphenous vein graft restenosis [28-30], thus it appears to be the advent of transition from BMS to DES in routine PCI practice.

However, we do not disregard an important problem of DES, that is, thrombosis. Especially subacute in-stent thrombosis could occur more frequently with DES than with BMS and a prolonged anti-platelet regimen is mandatory [31]. In spite of the use of anti-platelet agents, stent thrombosis occurs in approximately $1 \%$ of patients, with an increased likelihood of occurrence in high-risk patients or complex lesion subset of patients [32,33]. According to the previous report, triple anti-platelet therapy (aspirin + clopidogrel + cilostazol) seemed to be more effective in preventing thrombotic complications after stenting than dual anti-platelet agent [34], but latterly a case report showed a patient with subacute stent thrombosis involv- ing two different arteries simultaneously under the use of triple anti-platelet regimen [31]. Therefore, the promises of this potential panacea - DES, have been recently attenuated by the specter of late and very late stent thrombosis because of anti-platelet discontinuation [35-38]. However, the large-scale clinical trials and pool analysis demonstrated that the beneficial effect of DES on reducing the need for new revascularization compared with BMS extends to 4 years without evidence of a worse safety profile including thrombosis [39-42].

In our study, the specific lesion was choiced in the nondiabetic patients, and both BMS group and DES group had similar post-procedural outcomes including balloon predilatation $(\%)$, stent length $(\mathrm{mm})$, stent diameter $(\mathrm{mm})$, post-dilatation (\%), vessel dissection (\%) and postprocedural residual stenosis (\%), finally we found that the both groups had similar acute and subacute thrombosis (\%), late thrombosis (\%), in-segment restenosis (\%), TLR(\%), composite of cardiac death or Re-MI (\%) at 6-month fol- 


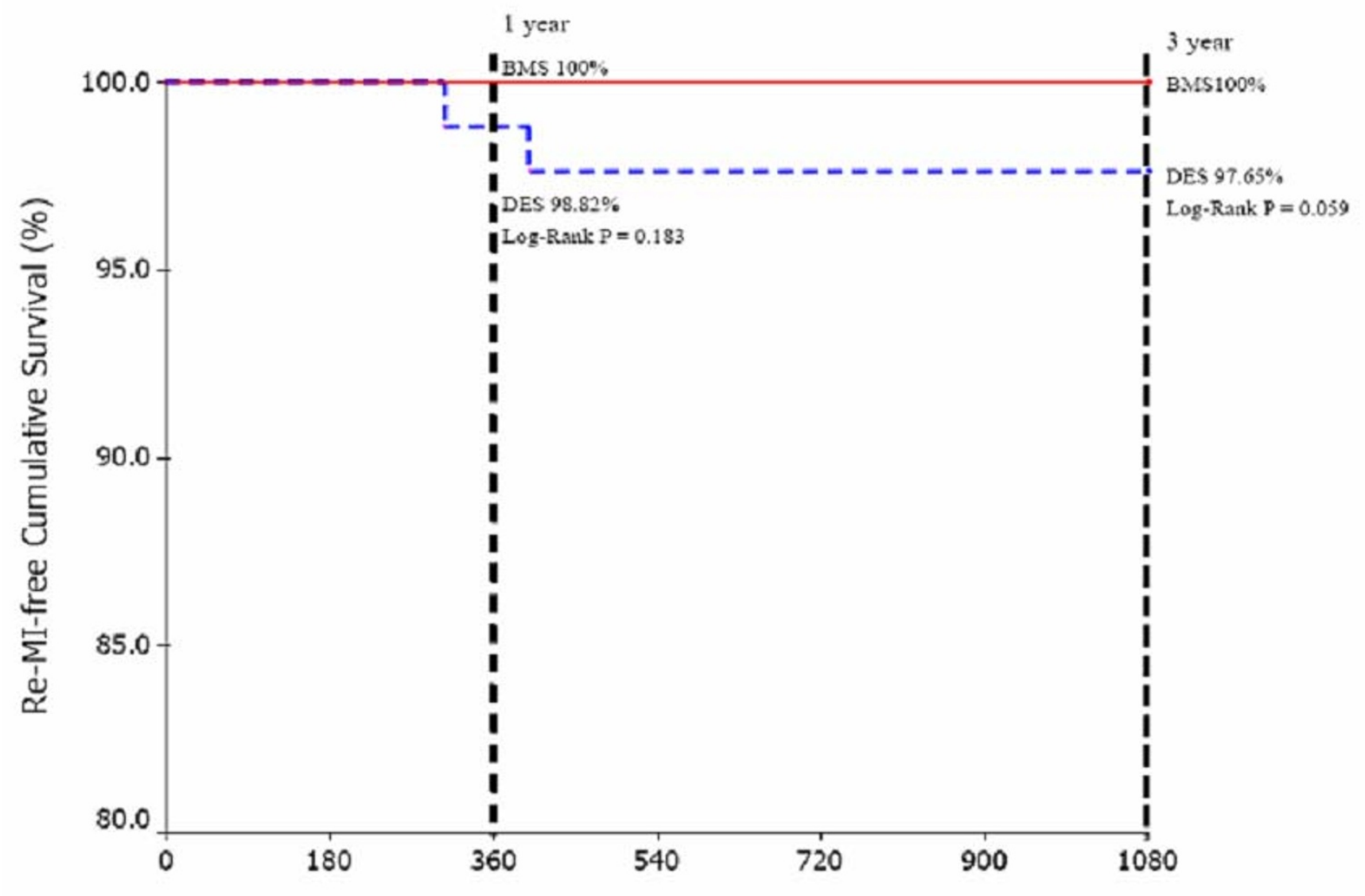

Time days

\section{Figure 3}

The Re-MI-free cumulative survival between BMS group and DES group at I-year and 3-year follow-up.

low-up and Re-MI (\%), cardiac death (\%), TLR (\%) as well as MACE (\%) at 1 - and 3-year follow-up, so were the cardiac death-free and TLR-free cumulative survival rate, however, there was a trend towards a decrease of Re-MIfree cumulative survival rate in the DES group compared with the BMS group at 1- and 3-year follow-up (all P > 0.05), we presumed that the Re-MI might be associated with very late thrombosis. In view of less cost, short-term anti-platelet regimen, less thrombosis incidence, similar restenosis rate and TLR rate in BMS compared with DES, suggesting that BMS may has similar efficacy and superior safety compared with DES at 3-year follow up, thus the nondiabetic patients with a simple de novo lesion in the middle and large vessel seem to have other benefit from BMS instead of DES in real world.

\section{Limitation}

Firstly, we investigated the non-diabetic patients with specific lesion in real world, the design of this trial was not randomized controlled trial (RCT), thereby the patients in
BMS group had lower hypercholesteremia rate $(22.0 \%$ vs $38.8 \%, \mathrm{P}=0.006)$ than DES group in baseline clinical characteristics, thereafter it is necessary for the RCT trials' investigation. Secondly, this is a small population and single medical center of investigation, thus it needs the large-scale trials to validate these findings. Thirdly, this study did not present very late thrombosis data, though it was few of incidence, the very late thrombosis should be investigated in future trials.

\section{Conclusion}

The single BMS has similar efficacy and safety to single DES in non-diabetic patients with a simple de novo lesion in the middle and large vessel at short- and long-term follow-up.

\section{Authors' contributions}

JLC, SBQ, XWQ, MY, JC, YJW, HBL, JiQY, SJY, JJL, JD and RLG carried out the relevant PCI procedures, BX participated in the design of the study, collected and managed 
the relevant data, YJY conceived of the study, participated in its design and coordination, and revised this manuscript. All authors read and approved the final manuscript.

\section{Acknowledgements}

We are very grateful to the staff in the department of cardiology and catheterization laboratory, Fu Wai Hospital, Chinese Academy of Medical Sciences, who contributed to complete the present study,

\section{References}

I. Moses JW, Leon MB, Popma JJ, Fitzgerald PJ, Holmes DR, O'Shaughnessy C, Caputo RP, Kereiakes DJ, Williams DO, Teirstein PS, Jaeger $\mathrm{JL}$, Kuntz RE: Sirolimus-eluting stents versus standard stents in patients with stenosis in a native coronary artery. $N$ Engl J Med 2003, 349( I 4): I3 I 5-23.

2. Holmes DR Jr, Leon MB, Moses JW, Popma JJ, Cutlip D, Fitzgerald PJ, Brown C, Fischell T, Wong SC, Midei M, Snead D, Kuntz RE: Analysis of I-year clinical outcomes in the SIRIUS trial: a randomized trial of a sirolimus-eluting stent versus a standard stent in patients at high risk for coronary restenosis. Circulation 2004, I 09(5):634-40.

3. Weisz G, Leon MB, Holmes DR Jr, Kereiakes DJ, Clark MR, Cohen BM, Ellis SG, Coleman P, Hill C, Shi C, Cutlip DE, Kuntz RE, Moses JW: Two-year outcomes after sirolimus-eluting stent implantation: results from the Sirolimus-Eluting Stent in de Novo Native Coronary Lesions (SIRIUS) trial. J Am Coll Cardiol 2006, 47(7): I350-5.

4. Lemos PA, Saia F, Ligthart JM, Arampatzis CA, Sianos G, Tanabe K, Hoye A, Degertekin M, Daemen J, McFadden E, Hofma S, Smits PC, de Feyter P, Giessen WJ van der, van Domburg RT, Serruys PW: Coronary restenosis after sirolimus-eluting stent implantation: morphological description and mechanistic analysis from a consecutive series of cases. Circulation 2003, I 08(3):257-60.

5. Colombo A, Orlic D, Stankovic G, Corvaja N, Spanos V, Montorfano M, Liistro F, Carlino M, Airoldi F, Chieffo A, Di Mario C: Preliminary observations regarding angiographic pattern of restenosis after rapamycin-eluting stent implantation. Circulation 2003, 107(17):2178-80.

6. Pfisterer M, Brunner-La Rocca HP, Buser PT, Rickenbacher P, Hunziker P, Mueller C, Jeger R, Bader F, Osswald S, Kaiser C: Late clinical events after clopidogrel discontinuation may limit the benefit of drug-eluting stents: an observational study of drug-eluting versus bare-metal stents. J Am Coll Cardiol 2006, 48(I2):2584-9I.

7. Bavry AA, Kumbhani DJ, Helton TJ, Borek PP, Mood GR, Bhatt DL: Late thrombosis of drug-eluting stents: a meta-analysis of randomized clinical trials. Am J Med 2006, I I 9( I 2): |056-6I.

8. Mehran R, Dangas G, Abizaid AS, Mintz GS, Lansky AJ, Satler LF, Pichard AD, Kent KM, Stone GW, Leon MB: Angiographic patterns of in-stent restenosis: classification and implications for long-term outcome. Circulation 1999, I00( I 8): 1872-8.

9. Elezi S, Dibra A, Mehilli J, Pache J, Wessely R, Schömig A, Kastrati A: Vessel size and outcome after coronary drug-eluting stent placement: results from a large cohort of patients treated with sirolimus- or paclitaxel-eluting stents. J Am Coll Cardiol 2006, 48(7): I 304-9.

10. Ryan TJ, Faxon DP, Gunnar RM, Kennedy JW, King SB 3rd, Loop FD, Peterson KL, Reeves TJ, Williams DO, Winters WL Jr, et al.: Guidelines for percutaneous transluminal coronary angioplasty. A report of the American College of Cardiology/American Heart Association Task Force on Assessment of Diagnostic and Therapeutic Cardiovascular Procedures (Subcommittee on Percutaneous Transluminal Coronary Angioplasty). Circulation 1988, 78(2):486-502.

II. Ellis SG, Vandormael MG, Cowley MJ, DiSciascio G, Deligonul U, Topol EJ, Bulle TM: Coronary morphologic and clinical determinants of procedural outcome with angioplasty for multivessel coronary disease. Implications for patient selection. Circulation 1990, 82(4): I 193-202.

12. EPISTENT Investigators: Randomised placebo-controlled and balloon-angioplasty-controlled trial to assess safety of coro- nary stenting with use of platelet glycoprotein-Ilb/IIla blockade. Lancet I998, 352(9 | 22):87-92.

13. Stone GW, Ellis SG, Cox DA, Hermiller J, O'Shaughnessy C, Mann JT, Turco M, Caputo R, Bergin P, Greenberg J, Popma JJ, Russell ME: A polymer-based, paclitaxel-eluting stent in patients with coronary artery disease. N Engl I Med 2004, 350(3):22I-3I.

14. Foley DP, Melkert R, Serruys PW: Influence of coronary vessel size on renarrowing process and late angiographic outcome after successful balloon angioplasty. Circulation 1994, 90(3): |239-5 |.

15. Sousa JE, Costa MA, Abizaid A, Abizaid AS, Feres F, Pinto IM, Seixas AC, Staico R, Mattos LA, Sousa AG, Falotico R, Jaeger J, Popma JJ, Serruys $\mathrm{PW}$ : Lack of neointimal proliferation after implantation of sirolimus-coated stents in human coronary arteries: a quantitative coronary angiography and three-dimensional intravascular ultrasound study. Circulation 200I, 103(2): 192-5.

16. Rensing BJ, Vos J, Smits PC, Foley DP, Brand MJ van den, Giessen WJ van der, de Feijter PJ, Serruys PW: Coronary restenosis elimination with a sirolimus eluting stent: first European human experience with 6-month angiographic and intravascular ultrasonic follow-up. Eur Heart J 200I, 22(22):2I 25-30.

17. Sousa JE, Costa MA, Abizaid AC, Rensing BJ, Abizaid AS, Tanajura LF, Kozuma K, Van Langenhove G, Sousa AG, Falotico R, Jaeger J, Popma JJ, Serruys PW: Sustained suppression of neointimal proliferation by sirolimus-eluting stents: one-year angiographic and intravascular ultrasound follow-up. Circulation 200I, 104(17):2007-II.

18. Regar E, Serruys PW, Bode C, Holubarsch C, Guermonprez JL, Wijns W, Bartorelli A, Constantini C, Degertekin M, Tanabe K, Disco C, Wuelfert E, Morice MC: Angiographic findings of the multicenter Randomized Study With the Sirolimus-Eluting Bx Velocity Balloon-Expandable Stent (RAVEL): sirolimus-eluting stents inhibit restenosis irrespective of the vessel size. Circulation 2002, 106(I 5): 1949-56.

19. Morice MC, Serruys PW, Sousa JE, Fajadet J, Ban Hayashi E, Perin M, Colombo A, Schuler G, Barragan P, Guagliumi G, Molnàr F, Falotico $\mathrm{R}$ : A randomized comparison of a sirolimus-eluting stent with a standard stent for coronary revascularization. $N$ Engl J Med 2002, 346(23): 1773-80.

20. Serruys PW, van Hout B, Bonnier H, Legrand V, Garcia E, Macaya C, Sousa E, Giessen W van der, Colombo A, Seabra-Gomes R, Kiemeneij F, Ruygrok P, Ormiston J, Emanuelsson H, Fajadet J, Haude M, Klugmann S, Morel MA: Randomised comparison of implantation of heparin-coated stents with balloon angioplasty in selected patients with coronary artery disease (Benestent II). Lancet 1998, 352(9 | 29):673-8|

21. Laham RJ, Carrozza JP, Berger C, Cohen DJ, Kuntz RE, Baim DS: Long-term (4- to 6-year) outcome of Palmaz-Schatz stenting: paucity of late clinical stent-related problems. J Am Coll Cardiol 1996, 28(4):820-6.

22. Edelman ER, Rogers C: Hoop dreams. Stents without restenosis. Circulation 1996, 94(6): I 199-202.

23. Kastrati A, Schömig A, Elezi S, Schühlen H, Dirschinger J, Hadamitzky $\mathrm{M}$, Wehinger A, Hausleiter J, Walter H, Neumann FJ: Predictive factors of restenosis after coronary stent placement. J Am Coll Cardiol 1997, 30(6): | 428-36.

24. Bauters C, Hubert E, Prat A, Bougrimi K, Van Belle E, McFadden EP, Amouyel P, Lablanche JM, Bertrand M: Predictors of restenosis after coronary stent implantation. J Am Coll Cardiol 1998, $3 I(6): 129 \mid-8$.

25. Colombo A, Drzewiecki J, Banning A, Grube E, Hauptmann K, Silber S, Dudek D, Fort S, Schiele F, Zmudka K, Guagliumi G, Russell ME: Randomized study to assess the effectiveness of slow- and moderate-release polymer-based paclitaxel-eluting stents for coronary artery lesions. Circulation 2003, 108(7):788-94.

26. Halkin A, Stone GW: Polymer-based paclitaxel-eluting stents in percutaneous coronary intervention: a review of the TAXUS trials. J Interv Cardiol 2004, I 7(5):27I-82.

27. Jonas M, Resnic FS, Levin AD, Arora N, Rogers CD: Transition from bare metal to drug eluting stenting in contemporary US practice: effect on incidence and predictors of clinically driven target lesion revascularization. Catheter Cardiovasc Interv 2007, 70(2): I75-83.

28. Mishra S, Wolfram RM, Torguson R, Chu WW, Xue Z, Gevorkian N, Donekal S, Chan R, Pichard AD, Satler LF, Kent KM, Waksman R: Comparison of effectiveness and safety of drug-eluting stents 
versus vascular brachytherapy for saphenous vein graft instent restenosis. Am J Cardiol 2006, 97(9): I303-7.

29. Holmes DR Jr, Teirstein P, Satler L, Sketch M, O'Malley J, Popma JJ, Kuntz RE, Fitzgerald PJ, Wang H, Caramanica E, Cohen SA: Sirolimus-eluting stents vs vascular brachytherapy for instent restenosis within bare-metal stents: the SISR randomized trial. JAMA 2006, 295(II):1264-73.

30. Dibra A, Kastrati A, Alfonso F, Seyfarth M, Pérez-Vizcayno MJ, Mehilli J, Schömig A: Effectiveness of drug-eluting stents in patients with bare-metal in-stent restenosis: meta-analysis of randomized trials. J Am Coll Cardiol 2007, 49(5):616-23.

31. Moon JY, Chung JW, Kim JH, Ahn YK, Jeong MH: Simultaneous subacute stent thrombosis of two sirolimus-eluting stents in a patient treated by ReoPro, thrombus aspiration and triple anti-platelet agents. Int / Cardiol in press. 2007 Oct I

32. Farb A, Boam AB: Stent thrombosis redux - the FDA perspective. N Engl J Med 2007, 356( I0):984-7.

33. Jeremias A, Sylvia B, Bridges J, Kirtane AJ, Bigelow B, Pinto DS, Ho KK, Cohen DJ, Garcia LA, Cutlip DE, Carrozza JP Jr: Stent thrombosis after successful sirolimus-eluting stent implantation. Circulation 2004, 109(16):1930-2.

34. Lee SW, Park SW, Hong MK, Kim YH, Lee BK, Song JM, Han KH, Lee CW, Kang DH, Song JK, Kim J], Park SJ: Triple versus dual antiplatelet therapy after coronary stenting: impact on stent thrombosis. J Am Coll Cardiol 2005, 46( I 0): 1833-7.

35. Chen JP: Very late drug-eluting stent thrombosis and cardiogenic shock: I,249 days after implantation. I Invasive Cardiol 2007, I 9(I 2):E38I-4.

36. Zhang F, Qian J, Ge J: Very late stent thrombosis in late stent malapposition after sirolimus-eluting stent implantation. Int Heart ] 2007, 48(5):59|-6.

37. Pfisterer M, Brunner-La Rocca HP, Buser PT, Rickenbacher P, Hunziker P, Mueller C, Jeger R, Bader F, Osswald S, Kaiser C: Late clinical events after clopidogrel discontinuation may limit the benefit of drug-eluting stents: an observational study of drug-eluting versus bare-metal stents. J Am Coll Cardiol 2006, 48(I2):2584-9|.

38. Lagerqvist B, James SK, Stenestrand U, Lindbäck J, Nilsson T, Wallentin L: Long-term outcomes with drug-eluting stents versus bare-metal stents in Sweden. N Engl J Med 2007, 356(10): 1009-19.

39. Marzocchi A, Saia F, Piovaccari G, Manari A, Aurier E, Benassi A, Cremonesi A, Percoco G, Varani E, Magnavacchi P, Guastaroba P, Grilli $R$, Maresta $A$ : Long-term safety and efficacy of drug-eluting stents: two-year results of the REAL (REgistro AngiopLastiche dell'Emilia Romagna) multicenter registry. Circulation 2007, I I5(25):318I-8.

40. Jensen LO, Maeng M, Kaltoft A, Thayssen P, Hansen HH, Bottcher M, Lassen JF, Krussel LR, Rasmussen K, Hansen KN, Pedersen L, Johnsen $S P$, Soerensen HT, Thuesen L: Stent thrombosis, myocardial infarction, and death after drug-eluting and bare-metal stent coronary interventions. J Am Coll Cardiol 2007, 50(5):463-70.

41. Stone GW, Moses JW, Ellis SG, Schofer J, Dawkins KD, Morice MC, Colombo A, Schampaert E, Grube E, Kirtane AJ, Cutlip DE, Fahy M, Pocock SJ, Mehran R, Leon MB: Safety and efficacy of sirolimusand paclitaxel-eluting coronary stents. N Engl J Med 2007, 356(10):998-1008.

42. Mauri L, Hsieh WH, Massaro JM, Ho KK, D'Agostino R, Cutlip DE: Stent thrombosis in randomized clinical trials of drug-eluting stents. N Engl J Med 2007, 356(10):1020-9. http://www.translational-medicine.com/content/6/1/42

\section{Publish with Bio Med Central and every scientist can read your work free of charge}

"BioMed Central will be the most significant development for disseminating the results of biomedical research in our lifetime."

Sir Paul Nurse, Cancer Research UK

Your research papers will be:

- available free of charge to the entire biomedical community

- peer reviewed and published immediately upon acceptance

- cited in PubMed and archived on PubMed Central

- yours - you keep the copyright

Submit your manuscript here:

http://www.biomedcentral.com/info/publishing_adv.asp
BioMedcentral 